\title{
Dehydration transformation in Ca-montmorillonite
}

\author{
P BALA, B K SAMANTARAY* and S K SRIVASTAVA ${ }^{\dagger}$ \\ *Department of Physics and Meteorology, Department of Chemistry, Indian Institute of Technology, \\ Kharagpur 721 302, India
}

MS received 4 September 1999; revised 1 December 1999

\begin{abstract}
The present work deals with the dehydration transformation of Ca-montmorillonite in the temperature range $30^{\circ}-500^{\circ} \mathrm{C}$. Thermal, infrared (IR), and X-ray diffraction (XRD) analyses were used to describe the thermal transformation. The microstructural and layer disorder parameters like crystallite size, r.m.s. strain $\left(\left\langle e^{2}\right\rangle^{1 / 2}\right)$, variation of interlayer spacing $(g)$, and proportion of planes which were affected by the defect $(\gamma)$, have all been calculated from the (001) basal reflection using the method of variance and Fourier line shape analysis. These investigations revealed that sample underwent transformation from hydrated phase to dehydrated phase at $200^{\circ} \mathrm{C}$, and as a consequence, its basal spacing collapsed from $16.02 \AA\left(30^{\circ} \mathrm{C}\right)$ to around $10 \AA\left(200^{\circ} \mathrm{C}\right)$. This transformation occurred through a wide range of temperature, i.e. within the range $120^{\circ}-200^{\circ} \mathrm{C}$. The crystallite size was maximum at room temperature $\left(30^{\circ} \mathrm{C}\right)$, however, the size decreased with increasing temperature in the hydrated phase, whereas the size increased with increasing temperature for the dehydrated phase. The $g, \gamma$ and $\left\langle e^{2}\right\rangle^{1 / 2}$ of the hydrated and the dehydrated phase increased and decreased, respectively with increase of heating temperature.
\end{abstract}

Keywords. Montmorillonite; layer disorder; microstructure parameters.

\section{Introduction}

The dehydration of smectite group of clay minerals, which is abundant in sedimentary settings, is of special interest to geologists because dehydration process influences the pore pressure in rock, affects rock strength and contributes to sub-surface fluid migration (Wu et al 1997) and diagenetic process (Ransom and Helgeson 1995). In addition, dehydration of smectites may also be important in predicting their behaviour while they are being transported down subduction zones at continental margins (Koster van Groos and Guggenheim 1989). Thus it is highly important to understand the behaviour of smectite with changing temperature.

Montmorillonite belongs to smectite group of clay minerals which has a 2:1 type of layer structure. It is comprised of negatively charged silica sheets held together by charge-balancing counterions such as $\mathrm{Mg}^{2+}, \mathrm{Na}^{+}$, and $\mathrm{Ca}^{2+}$. The general chemical formula of the montmorillonite is $\left(\mathrm{M}_{y}^{+} \cdot n \mathrm{H}_{2} \mathrm{O}\right)\left(\mathrm{Al}_{4-y} \mathrm{Mg}_{y}\right) \mathrm{Si}_{8} \mathrm{O}_{20}(\mathrm{OH})_{4}$, where $\mathrm{M}\left(\mathrm{M}=\mathrm{Na}^{+}, \mathrm{Ca}^{2+}, \mathrm{Mg}^{2+}\right.$, etc $)$ is the interlayer cation. These interlayer cations balance the negative charges which are generated by the isomorphous substitution of $\mathrm{Mg}^{2+}$ and $\mathrm{Fe}^{2+}$ for $\mathrm{Al}^{3+}$ in the octahedral sheet; and $\mathrm{Al}^{3+}$ for $\mathrm{Si}^{4+}$ in the tetrahedral sheet. Besides the interlayer cations, the interlayer space of smectite group of clay minerals contains large amounts of water molecules.

*Author for correspondence
Montmorillonite has diverse applications in many fields like agriculture, oil industry, ceramic industry, etc. Recent applications of montmorillonite include its use for radioactive and nuclear waste treatment purposes (Kikuchi et al 1992; Sazarashi et al 1994), as chemical sensor (Oyama et al 1993), in cosmetic applications (Peker et al 1995), and in the field of catalysis (Choudary and Sudha 1996; Cramarossa et al 1997; Kotkar and Thakkar 1997; Ramchandani et al 1997; Lu et al 1998; Sato et al 1998; Zhang et al 1998; Boricha et al 1999; Iwamatsu et al 1999). In addition, preparation of organophilic montmorillonite, in the synthesis of polymeric nano composites, has also taken its due importance because of its improved properties (Akelah et al 1994; Kornmann et al 1998; Reichert et al 1998; Bala et al 1999; Noh et al 1999; Ray and Biswas 1999). In most of these applications, uses of montmorillonite are the consequence of its properties like plasticity, swelling, ion exchange, density, compaction, etc. These properties of montmorillonite are mainly governed by the interaction of the interlayer materials with the environment. Thus, the stability of interlayer materials, and knowing the interlayer environment with respect to temperature-more precisely, the effects of heat treatment and the consequent changes in their structure and physical properties-are of great importance for the use of montmorillonite clay. In fact, number of recent works regarding dehydration of montmorillonite have been reported (Huang et al 1994; Wu et al 1997; Bray et al 1998). Most of these works mainly deal with the interpretation of $d_{001}$ (basal spacing), and full width 
half maximum (FWHM) values of basal spacing, with change in temperature and pressure. Since the distribution of water and interlayer cations are heterogeneous along the $c$-axis (Lagaly 1981), a variation in the interlayer spacing is observed (Bray et al 1998), which should affect the reflections and, in particular the 001 reflection. Therefore, quantitative measurement of the variation in interlayer spacing and planes affected by such variation are important parameters for understanding the dehydration behaviour of montmorillonite. Moreover, Zhu et al (1999) reported that microstructure of montmorillonite plays a great role in improvement of mechanical properties of montmorillonite-polyamide hybrid materials. To the best of our knowledge, montmorillonite has not been investigated from the point of the above-mentioned layer disorders and microstructure parameters.

Therefore, the present work is aimed at investigating Ca-montmorillonite during the process of dehydration and the consequent changes in their microstructural and layer disorder parameters. For this purpose, X-ray line profile analysis technique has been used to calculate the microstructural parameters like crystallite size, r.m.s. strain, and layer disorder parameter like variation of interlayer spacing $(g)$ and proportions of planes affected by the defect $(\gamma)$ in the temperature range $30^{\circ}-500^{\circ} \mathrm{C}$. The sample has also been characterized by thermal and infrared analyses during dehydration.

\section{Experimental}

Ca-montmorillonite, $\mathrm{Ca}_{1 \cdot 01}\left(\mathrm{Al}_{2 \cdot 95} \mathrm{Fe}_{0 \cdot 25}^{3+} \mathrm{Fe}_{0 \cdot 04}^{2+} \mathrm{Mg}_{0.76}\right)\left(\mathrm{Al}_{0 \cdot 21}\right.$ $\left.\mathrm{Si}_{7.79}\right) \mathrm{O}_{20}(\mathrm{OH})_{4}$, supplied by Smithsonian Institute, USA, has been used in the present investigation. Thermogravimetric analysis (TGA) was carried out using DT40, SHIMADZU in the temperature range $20^{\circ}-980^{\circ} \mathrm{C}$ (heating rate $10^{\circ} \mathrm{C} / \mathrm{min}$ ) in air. The IR spectra of the samples (as $\mathrm{KBr}$ pellets) were recorded, using a Perkin-Elmer 883 infrared spectrometer, in the range from $200 \mathrm{~cm}^{-1}$ to $4000 \mathrm{~cm}^{-1}$. The amount of sample and $\mathrm{KBr}$ were same for all the compounds. For the purpose of dehydration, the finely powdered sample was divided into several portions. Each portion was then separately heated in a quartz crucible for $2 \mathrm{~h}$ each at the following temperatures: 80, $120,160,200,300$ and $500^{\circ} \mathrm{C}$, in an electric muffle furnace. The variation of temperature with furnace was $\pm 5^{\circ} \mathrm{C}$. On completion of heating, the samples were directly transformed to a desiccator so as to avoid reabsorbing of moisture.

The XRD studies for all these samples were performed in a dry atmosphere on Rigaku Diffractometer $(\mathrm{CuK} \alpha, \mathrm{Ni}$ filtered). The geometrical and background corrections of the intensity profiles were carried out by the methods described by Mitra and Bhattacherjee (1969, 1970). Since the reflections in the region $2 \theta<10^{\circ}$ are affected by Lorentz-polarization $\left(L_{\mathrm{p}}\right)$ factor (Stanjek et al 1992), $L_{\mathrm{p}}$ corrections were therefore also made for the 001 reflection of the samples.

Assuming that the broadening of the X-ray diffraction (XRD) line profile is due to presence of size and strain broadening, as well as broadening arising due to the variation of inter layer spacing $(d)$ values, the variance of the profile can be written as:

$$
W_{2 \theta}=\frac{\alpha \lambda}{2 \pi^{2} p^{\prime} \cos \theta}+\frac{S \lambda^{2}}{\cos ^{2} \theta},
$$

where

$$
S=\frac{\left\langle e^{2}\right\rangle-\beta_{d}^{2} / \pi^{2}}{d^{2}},
$$

and $p^{\prime}$ is the apparent crystallite size, $\alpha$ the angular range over which the intensity distribution is appreciable, $\left\langle e^{2}\right\rangle$ the mean square strain, $\lambda$ the wavelength of the X-ray, $\theta$ the Bragg angle, and $d$ the interplaner spacing. Thus if graphs of $W_{2 \theta}$ against $\alpha$ are plotted, their slope and intercepts on the $W_{2 \theta}$ axis will give $p^{\prime}$ and $\left\langle e^{2}\right\rangle$ respectively. Again

$$
\begin{aligned}
& \frac{1}{p^{\prime}}=\frac{1}{p}+\frac{\beta_{d}}{d}, \\
& g=\frac{1}{\pi l} \cot ^{-1} \frac{\pi \Delta}{\beta_{d}},
\end{aligned}
$$

and

$$
\gamma=\frac{\beta_{d}}{\sin ^{2}(\pi \cdot l \cdot g)},
$$

Here $p$ is the true particle size, whose value can be evaluated using Fourier line shape analysis, $\beta_{d}$ the integral width of the defect profile, $\Delta$ the measure of peak shift from the centroid of the diffraction profile, and $l$ the order of reflection (Srivastava et al 1997).

\section{Results and discussion}

Figure 1 represents the variation of weight loss (\%) with temperature for Ca-montmorillonite. It showed a significant weight loss in the temperature range $20^{\circ}-200^{\circ} \mathrm{C}$ $(\approx 20 \%)$. It was also observed that the loss was higher at $20^{\circ}-100^{\circ} \mathrm{C}(\approx 12 \%)$ when compared to $100^{\circ}-200^{\circ} \mathrm{C}$ $(\approx 8 \cdot 0 \%)$. Subsequently, a gradual weight loss from $200^{\circ} \mathrm{C}$ up to $600^{\circ} \mathrm{C}(\approx 5 \cdot 3 \%)$ was observed followed by relatively a rapid one from $600^{\circ} \mathrm{C}$ to $750^{\circ} \mathrm{C}(\approx 3 \cdot 0 \%)$. Thereafter it showed almost no further weight loss.

It may be interesting here to mention that montmorillonite structure contains three types of water molecules viz. free water molecules, hydrogen-bonded water molecules and water molecules strongly coordinated to the interlayer cations (Atkins et al 1983). Thus in the 
process of dehydration, free water molecules should be removed first followed by expulsion of hydrogenbonded/coordinated water molecules. The higher weight loss within the temperature range $20^{\circ}-100^{\circ} \mathrm{C}$ in present case is due to the removal of the free water molecules from the interlayer spaces. Thus the weight loss between $100^{\circ}-200^{\circ} \mathrm{C}$ may be due to the hydrogen-bonded and coordinated water molecules, which would finally result in the 'collapsed' structure (MacEwan and Wilson 1980). However, the possibility of removal of some of the hydrogen-bonded and coordinated water molecules in the lower temperature range too can not be ruled out. Koster van Groos and Guggenheim (1989) reported that in montmorillonite, dehydroxylation reaction takes place in the range $600^{\circ}-750^{\circ} \mathrm{C}$. Bray et al (1998) observed that the dehydration reaction does not have clear end point and therefore could not be analyzed by thermal analysis; while dehydroxylation begins before dehydration is complete. Thus in present investigation, it is inferred that $\mathrm{Ca}$ montmorillonite looses most of its interlayer water molecules around $200^{\circ} \mathrm{C}$. Beyond $200^{\circ} \mathrm{C}$ the weight loss is due to dehydroxylation the extent of which increases with increasing temperature up to $750^{\circ} \mathrm{C}$ (figure 1). It is also noted that the maximum dehydroxylation takes place between the temperature range $600^{\circ} \mathrm{C}$ and $750^{\circ} \mathrm{C}$. Thereafter it showed almost no weight loss. This is because of the fact that dehydration/dehydroxylation is completed by $750^{\circ} \mathrm{C}$.

Infrared analysis curves of untreated and heat-treated samples at different temperatures are shown in figure 2. The strong band near $1030 \mathrm{~cm}^{-1}$ is due to $\mathrm{Si}-\mathrm{O}-\mathrm{Si}$ stretching vibration, which corresponds to the characteristic band of montmorillonite. The bands due to free (or weakly hydrogen-bonded water molecule to the surface oxygen of tetrahedral sheet) water molecules, water-water hydrogen bond $\left(\mathrm{M}^{n+}-\mathrm{O}-\mathrm{H}-\mathrm{O}-\mathrm{H}-\right)$ and water bending modes are observed near 3620, 3445 and $1635 \mathrm{~cm}^{-1}$, respectively (Farmer 1974). It is observed from the present investigation that the intensity of these three bands decreased with respect to the intensity of $\mathrm{Si}-\mathrm{O}-\mathrm{Si}$ band for the sample heated at $160^{\circ} \mathrm{C}$ and at $500^{\circ} \mathrm{C}$, indicating that the water molecules from the interlayer spaces were removed. Since the Ca-montmorillonite loses

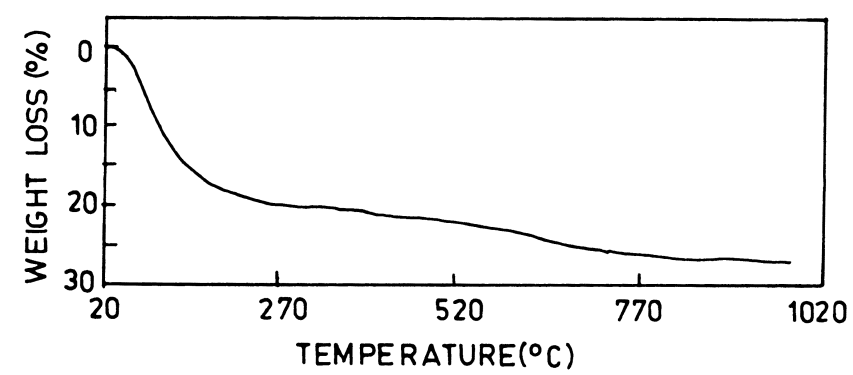

Figure 1. Thermogravimetric analysis (TGA) curves of pure Ca-montmorillonite. most of its interlayer water molecules around $200^{\circ} \mathrm{C}$ (MacEwan and Wilson 1980), the appearance of these bands at $500^{\circ} \mathrm{C}$ indicates the presence of trace water molecules. This is probably due to tetrahedral substitution which increases the charge on oxygens. At higher temperature these charges are localized on few of the oxygens (Farmer and Russell 1971) resulting in their forming strong hydrogen bonds to some of the $\mathrm{OH}$ groups that are not being removed. It is interesting to note that the bands near 915 and $840 \mathrm{~cm}^{-1}$, respectively, correspond to vibrational frequencies of $\mathrm{Al}_{2} \mathrm{OH}$ and $\mathrm{MgAlOH}$ (Farmer 1974). These bands disappear at $500^{\circ} \mathrm{C}$. The IR analysis at different temperatures prove the stability of the layer structure of Ca-montmorillonite up to the present experimental temperature range $\left(500^{\circ} \mathrm{C}\right)$.

The $\mathrm{X}$-ray-line profile of the sample is given in figure 3 . The X-ray pattern of a sample $\left(30^{\circ} \mathrm{C}\right)$ shows a peak at $2 \theta=5 \cdot 44^{\circ}$, which corresponds to 001 basal reflection. This is shifted to higher angles $\left(2 \theta=5.73^{\circ}\right)$ at $80^{\circ} \mathrm{C}$. The peak at $30^{\circ} \mathrm{C}$ and $80^{\circ} \mathrm{C}$ is highly asymmetric. At $120^{\circ} \mathrm{C}$ and $160^{\circ} \mathrm{C}$, probably the combination of two peaks are observed. The $2 \theta$ values of these two peaks are obtained by the deconvolution process. The values of $2 \theta$ at $120^{\circ} \mathrm{C}$ are $5.88^{\circ}$ and $8.16^{\circ}$ respectively; whereas at $160^{\circ} \mathrm{C}$ the values are $5.96^{\circ}$ and $8.52^{\circ}$, respectively. The intensity of the peaks (both old and new) at $120^{\circ} \mathrm{C}$ and $160^{\circ} \mathrm{C}$ are very weak. At $200^{\circ} \mathrm{C}$, the parent peak $\left(2 \theta=5 \cdot 44^{\circ}\right)$ disappeared and the distinct peak at $2 \theta=8.65^{\circ}$ is observed. Beyond $200^{\circ} \mathrm{C}$ temperature, the new peak becomes more pro-

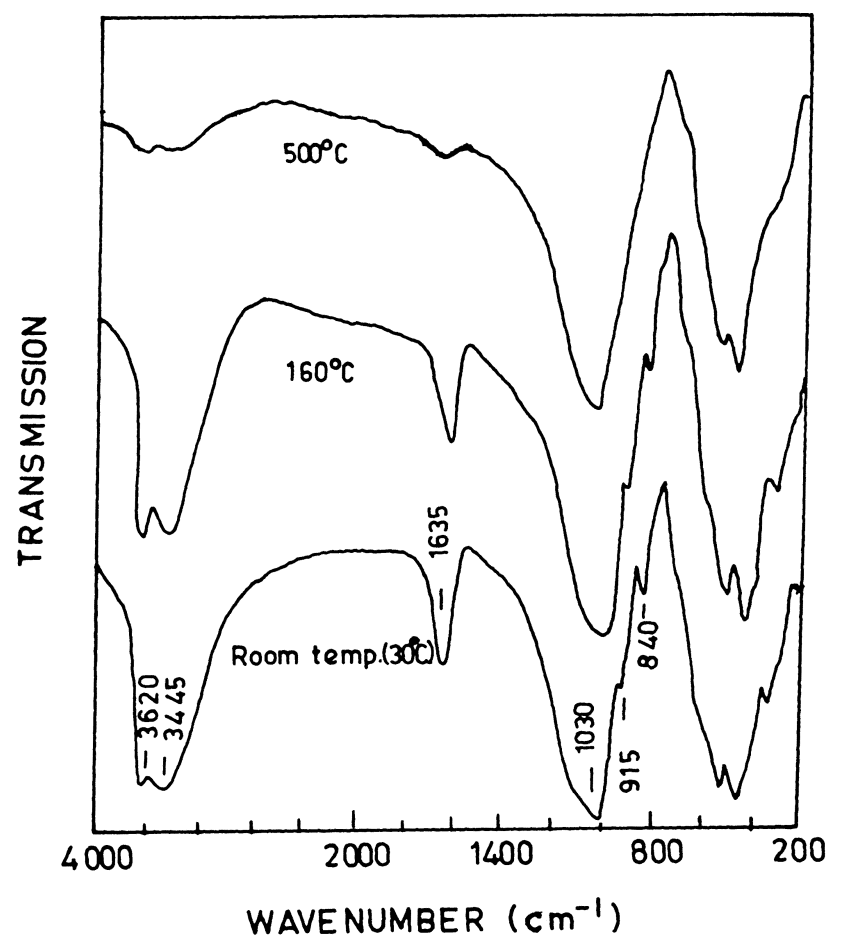

Figure 2. Infrared (IR) spectra of Ca-montmorillonite at room temperature $\left(30^{\circ} \mathrm{C}\right)$ and heated at different temperatures. 
minent. Thus, it is clear from the $\mathrm{X}$-ray-line profiles that the basal reflection of sample $\left(2 \theta=8.65\right.$ at $\left.30^{\circ} \mathrm{C}\right)$ is shifted towards the higher angle region with increase of heating temperature, reaching the value $2 \theta=5.96^{\circ}$ at $160^{\circ} \mathrm{C}$. At the same time a new phase begins to develop at $120^{\circ} \mathrm{C}$, which is completed at $200^{\circ} \mathrm{C}$. The presence of such dehydration phase transition has also been reported by Koster van Groos and Guggenheim (1989). For the sake of explanation, the two phases at $2 \theta=5.44^{\circ}$ (unheated sample) and $2 \theta=8.65^{\circ}$ (at $120^{\circ} \mathrm{C}$ ) were denoted as I (hydrated phase) and II (dehydrated phase), respectively. Initially the sample is characterized by the crystallites of phase I, upon heating of the sample, its interlayer water molecules are slowly expelled, and this expulsion of water takes place to a greater extent above $80^{\circ} \mathrm{C}$. Probably at

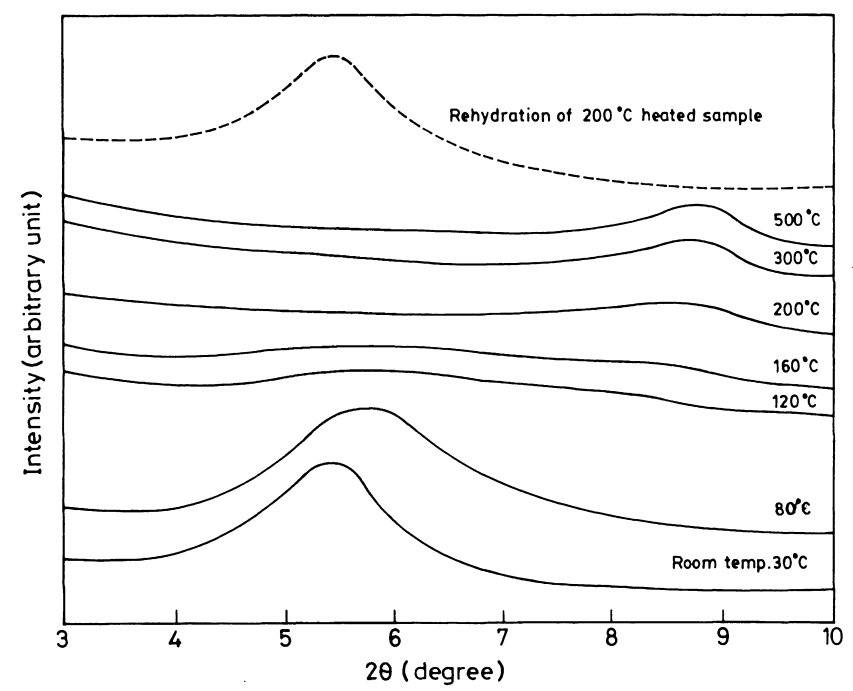

Figure 3. X-ray diffraction (XRD) profiles of Ca-montmorillonite at room temperature $\left(30^{\circ} \mathrm{C}\right)$ and heated at different temperatures.

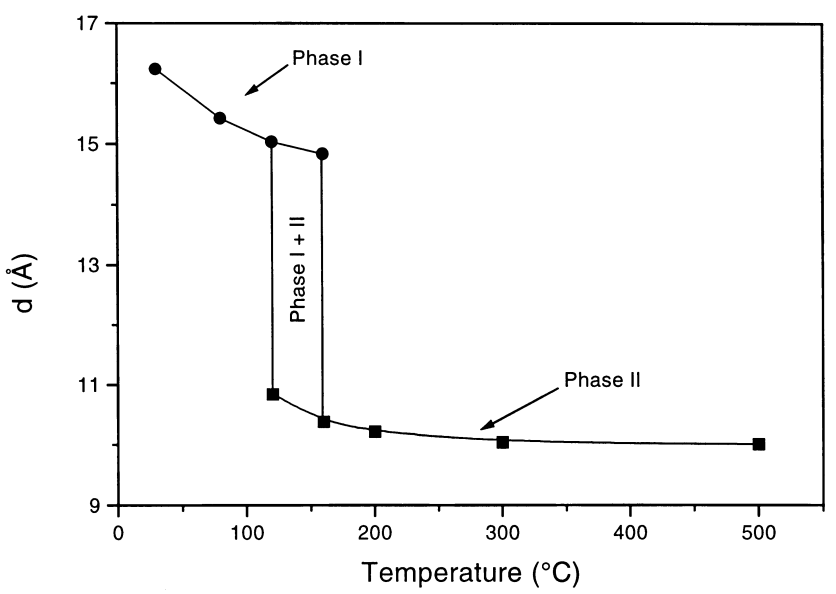

Figure 4. Variation of interplanar spacing $(d)$ for Ca-montmorillonite as a function of temperature. $120^{\circ} \mathrm{C}$ temperature, large number of crystallites of phase I lose most of their interlayer water and are converted into dehydrated phase, i.e. phase II. This transformation of crystallites from phases I to II continues up to $160^{\circ} \mathrm{C}$. Above this temperature transformation becomes complete; showing disappearance of peak in phase I, and subsequently, there appears a peak corresponding to phase II, which became distinct at $200^{\circ} \mathrm{C}$.

The variation in $d_{001}$ values for both phases I and II is given in figure 4 . It is observed that $d_{001}$ value for phase I decreases with increasing heating temperature up to $160^{\circ} \mathrm{C}$. A fast decrease of $d_{001}$ value is observed initially in phase I. Similar types of observations were also noted in the temperature range $120^{\circ}-500^{\circ} \mathrm{C}$ for phase II with the only difference that decrease in $d$ was not so rapid as seen earlier (phase I). It may also be noted that $d_{001}$ values for phase II remain almost constant beyond $200^{\circ} \mathrm{C}$. It may be interesting to mention here that $d_{001}$ value $(\approx 10 \AA)$ of the sample of phase II (at $200^{\circ} \mathrm{C}$ ) matched well with dehydrated phase of montmorillonites (MacEwan and Wilson 1980). The reversibility of the dehydration process under prolonged exposure to the moisture of the dehydrated samples was observed by keeping the samples in air $(95 \%$ R.H). The X-ray diffraction patterns of a typical representative moisture exposed sample $\left(200^{\circ} \mathrm{C}\right)$ is also shown in figure 3 and it is observed that 001 peak is restored back to original position.

The 001 reflections of untreated and heat-treated Camontmorillonite were analyzed by variance method, described earlier, to calculate the different microstructural parameters. As the method of variance is sensitive to variation near the tails, the variance analysis was carried out after carefully correcting the background. Graphs were plotted using $W_{2 \theta}$ as the ordinate and $\alpha$ (range) as the abscissa by emphasizing the points corresponding to the tail. A typical variance-range plot is shown in figure 5. The linear variance-range plot establishes the correctness of the background correction. True crystallites size were

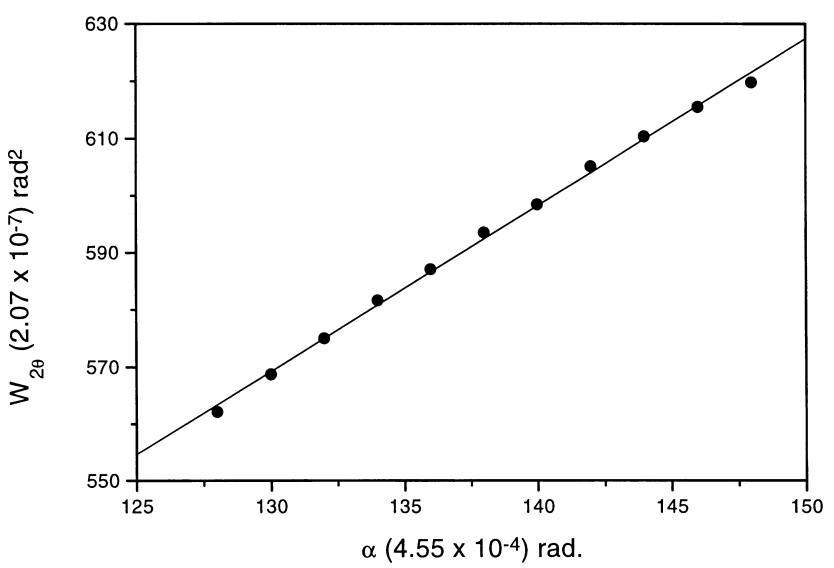

Figure 5. Variance range plot for 001 reflection of Ca-montmorillonite at room temperature $\left(30^{\circ} \mathrm{C}\right)$. 
calculated from Fourier line shape similar to that described by Warren and Averbach (1950).

The variation of crystallite size in variance method, Fourier method, and r.m.s. strain with temperature are shown in figures 6,7 and 8 , respectively. The variance crystallites size of the untreated sample is $59 \AA$ and it decreased with increase of heating temperature and finally reached the value $22 \AA$ at $160^{\circ} \mathrm{C}$. Here it is interesting to note that the value of crystallite size of phase II is $22 \AA$ at $120^{\circ} \mathrm{C}$ and it increased with increase of heating temperature. The Fourier crystallite size is observed to be higher and also shows almost the same type of trend, but the variation of crystallite in this method is not so significant in phase I but is more significant in case of variance crystallite size. This is attributed to the fact that variance crystallite size is highly dependent on the defects parameters whereas Fourier crystallite is not so. The r.m.s. strain of the sample shows the reverse type of

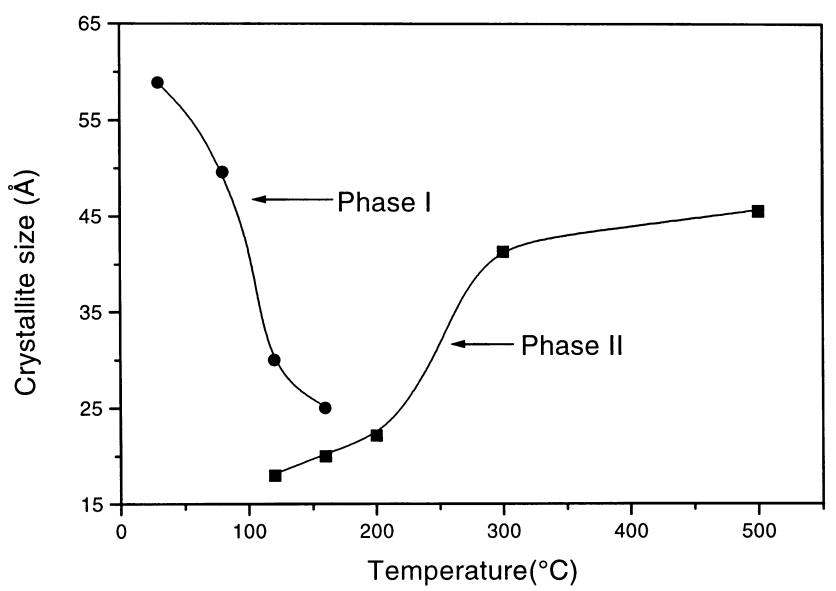

Figure 6. Plot of the crystallite size obtained by the method of variance $\left(p^{\prime}\right)$ vs the temperature at which Ca-montmorillonite samples were heated.

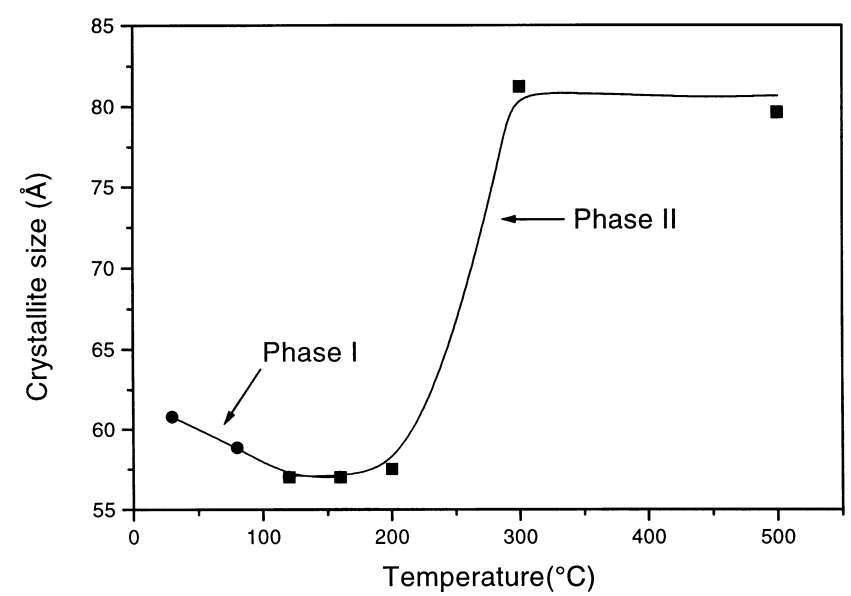

Figure 7. Plot of the crystallite size obtained by the Fourier method $(p)$ vs the temperature at which Ca-montmorillonite samples were heated. behaviour of the crystallites size, i.e. when the crystallite size is high the r.m.s. strain is low and when the crystallite size is low it shows the high value. The higher values of crystallite size and lower values of r.m.s. strain for untreated sample show that Ca-montmorillonite structure is more at equilibrium at room temperature. With increase of heating temperature, crystallite size decreases and r.m.s. strain increases and the system passes through a nonequilibrium state which reaches maximum between $100^{\circ}-200^{\circ} \mathrm{C}$. Beyond $200^{\circ} \mathrm{C}$, the system again shows a trend to equilibrium state giving a larger crystallite size and lower strain values.

The change of variation of interlayer spacing $(g)$ and proportion of planes affected by such variations $(\gamma)$ are shown in figures 9 and 10, respectively. The values of these layer disorder parameters are observed to be minimum for the untreated samples. The value of $g$ increased with increase of heating temperature in phase I, which suggests that with increase of heating temperature stacking of layers along $c$-axis become more heterogeneous. The corresponding increase in $\gamma$ indicates that this heterogeneity spreads through larger area of the crystallite. At $120^{\circ} \mathrm{C}$ and $160^{\circ} \mathrm{C}$, mixture of two types of crystallite (phases I and II) are observed. The value of $g$ and $\gamma$ at $120^{\circ} \mathrm{C}$ and $160^{\circ} \mathrm{C}$ for phase $\mathrm{I}$ is greater than that of phase II, indicating that if the structure loses most of its inter-layer water its structure becomes highly disordered. Beyond $200^{\circ} \mathrm{C}$ the phase I disappears and only phase II is observed. The value of $g$ for phase II decreases gradually but $\gamma$ remains almost constant up to $200^{\circ} \mathrm{C}$, after that it decreased drastically up to $300^{\circ} \mathrm{C}$ and beyond this temperature it becomes again constant. These indicate that the crystallites of phase II are initially more disordered and with increase of heating temperature some sort of orientation takes place which gives a homogeneous stacking of layers. Bray et al (1998) from their qualitative analysis of peak shape concluded that hydrated $\mathrm{Ca}$ -

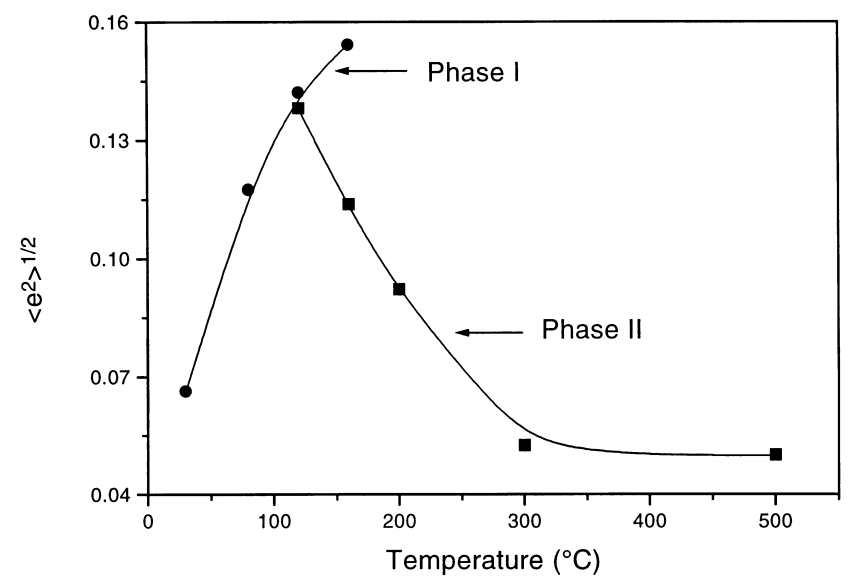

Figure 8. Plot of the r.m.s. strain $\left(\left\langle e^{2}\right\rangle^{1 / 2}\right)$ vs the temperature at which $\mathrm{Ca}$-montmorillonite samples were heated. 


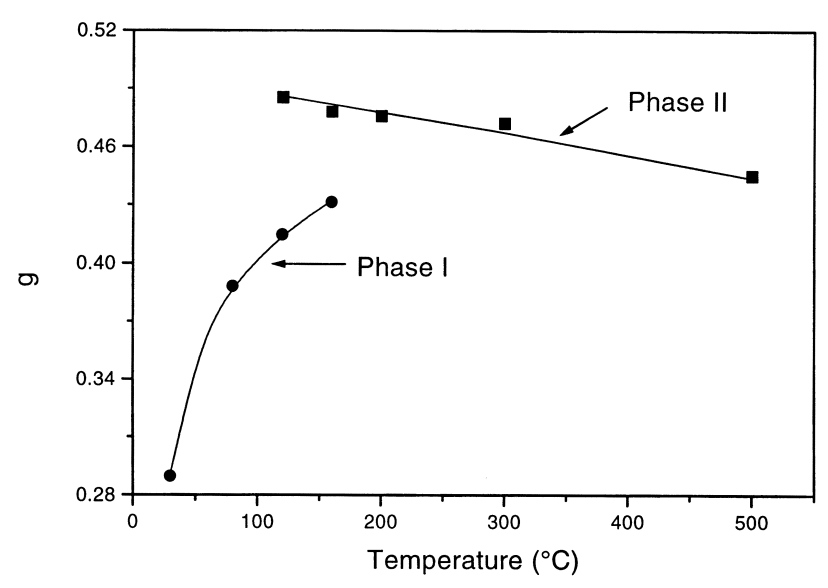

Figure 9. Plot of $g$ vs the temperature at which Ca-montmorillonite samples were heated.

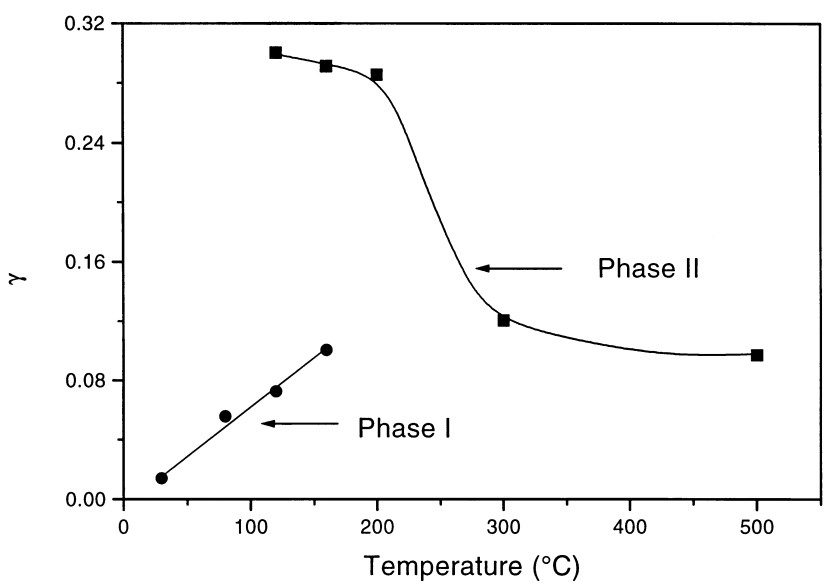

Figure 10. Plot of $\gamma$ vs the temperature at which Ca-montmorillonite samples were heated.

montmorillonite possesses high structural correlation along $c$-axis, giving a homogeneous structure and when the dehydration takes place, the system becomes heterogeneous, and after that the system approaches to final state and it becomes less heterogeneous. In the present investigations it is clearly observed from the lower $g$ and $\gamma$ values at $30^{\circ} \mathrm{C}$ that Ca-montmorillonite shows more homogeneity of its structure on hydrated state and the system shows more heterogeneity with increase of heating temperature giving an increasing value of $g$ and $\gamma$. It is also observed from the value of $g$ and $\gamma$ for phase II, system achieves the homogeneity again, which becomes more considerable beyond $200^{\circ} \mathrm{C}$.

\section{Conclusions}

Thermogravimetric analysis of the sample indicates the removal of free water molecules around $100^{\circ} \mathrm{C}$, and hydrogen bonded and coordinated water molecules around $200^{\circ} \mathrm{C}$. Dehydroxylation of the sample takes place through a wide range of temperature, but maximum dehydroxylation takes place at $600^{\circ}-750^{\circ} \mathrm{C}$. The X-ray analysis of the sample indicates that the sample transforms from hydrated phase to dehydrated phase at $200^{\circ} \mathrm{C}$. But it is also observed that this transformation takes place through a wide range of temperature $\left(120^{\circ}-200^{\circ} \mathrm{C}\right)$. The size of the crystallites decrease with increase of heating temperature in hydrated phase but it increases in dehydrated phase. The values of $g$ and $\gamma$ at different stages of dehydration indicate that the Ca-montmorillonite possesses relatively more uniform stacking of layers along $c$-axis at room temperature, with increase of heating temperature this uniformity loses and maximum break down of uniformity observed during the phase change $\left(120^{\circ}-200^{\circ} \mathrm{C}\right)$, beyond the phase transition temperature $\left(120^{\circ}-200^{\circ} \mathrm{C}\right)$ the system again shows the uniformity trends of stacking of its layers along $c$-axis. The main achievement of present investigations is the quantitative measurement of variation of interlayer spacing and proportions of planes affected by such variation which give a direct view to the interlayer environment during dehydration process and are in agreement with the observations made by Bray et al (1998) from a qualitative examination of synchrotron radiation peak shapes.

\section{References}

Akelah A, Kelly P, Qutubuddin S and Moet A 1994 Clay Miner. 29169

Atkins M P, Smith D J H and Westlake D J 1983 Clay Miner. 18423

Bala P, Samantaray B K and Srivastava S K 1999 J. Phys. Chem. Minerals (communicated)

Boricha A B, Mody H M, Das A and Bajaj H C 1999 Appl. Catal. A - General 1795

Bray H J, Redfern S A T and Clark S M 1998 Mineral. Mag. 62 647

Choudary B M and Sudha Y 1996 Synth. Commun. 262989

Cramarossa M R, Forti L and Ghelfi F 1997 Tetrahedron 53 15889

Farmer V C (ed.) 1974 The infrared spectra of minerals (London: Mineralogical Society) ch. 15

Farmer V C and Russell 1971 Trans. FaradaySoc. 672737

Huang W, Bassett W A and Wu T 1994 Am. Mineral. 79683

Iwamatsu E, Hayashi E, Sanada Y, Ahmed S, Ali S A, Lee A K K, Hamid H and Yoneda T 1999 Appl. Catal. A-General 179139

Kikuchi M, Chino K, Nishi T, Tsuchiya H, Sumitani N and Amano O 1992 J. Nucl. Sci. Technol. 291026

Kornmann X, Berglund L A, Sterte J and Giannelis E P 1998 Polym. Engg. Sci. 381351

Koster van Groos A F and Guggenheim S 1989 Am. Mineral. 74 627

Kotkar D and Thakkar N V 1997 Proc. Indian Acad. Sci. Chem. Sci. 10999 
Lagaly G 1981 Clay Miner. 161

Lu B, Li L J, Li T S and Li J T 1998 J. Chem. Res. S9 604

MacEwan D M C and Wilson M J 1980 Crystal structures of clay minerals and their X-ray identification (ed.) G W Brindley and G Brown (London: Mineralogical Society) p. 233

Mitra G B and Bhattacherjee S 1969 Am. Mineral. 541409

Mitra G B and Bhattacherjee S 1970 Acta Cryst. B26 2124

Noh M H, Jang L W and Lee D C 1999 J. Appl. Polym. Sci. 74 179

Oyama N, Takada K, Tatsuma T, Naoi K, Okajima T and Ohsaka T 1993 Sensors and Actuators B [Chemical] B13 372

Peker S, Yapan S and Besum N 1995 Colloids and surfaces APhysiochemical and Engineering Aspects 104249

Ramchandani R K, Uphade B S, Vinod M P, Wakharkar R D, Choudhary V R and Sudalai A 1997 Chem. Commun. 212071

Ransom B and Helgeson H C 1995 Am. J. Sci. 295245

Ray S and Biswas M 1999 J. Appl. Polym. Sci. 732971
Reichert P, Kressler J, Thomann R, Mulhaupt R and Stoppelmann G 1998 Acta Polym. 49116

Sato H, Hirose K, Nagai K, Yoshioka H and Nagaoka H 1998 Appl. Catal. A - General 175201

Sazarashi M, Ikeda Y, Seki R and Yoshikawa H 1994 J. Nucl. Sci. Technol. 31620

Srivastava S K, Mandal T K and Samantaray B K 1997 Synth. Metals 90135

Stanjek H, Niederbudde E A and Hausler W 1992 Clay Miner. 273

Warren B E and Averbach B L 1950 J. Appl. Phys. 21595

Wu T C, Bassett W A, Koster van Groos A F and Guggenheim S 1997 Am. Mineral. 8269

Zhang Z H, Li T S, Jin T S and Li J T 1998 J. Chem. Res. S10 640

Zhu Z, Yang Y, Yin J, Wang X, Ke Y and Qi Z 1999 J. Appl. Polym. Sci. 732063 